Moura, O., Moreno, J., Pereira, M., \& Simões, M. R. (2015). Developmental dyslexia and phonological processing in European Portuguese orthography. Dyslexia, 21(1), 60-79. doi:10.1002/dys.1489

\title{
Developmental Dyslexia and Phonological Processing in European Portuguese Orthography
}

\begin{abstract}
This study analyzed the performance of phonological processing, the diagnostic accuracy and the influence on reading in children who were native speakers of an orthography of intermediate depth. Portuguese children with developmental dyslexia (DD; $N=24$; aged 10 to 12 years), chronological-age-matched controls (CA; $N=24$; aged 10 to 12 years) and readinglevel-matched controls (RL; $N=24$; aged 7 to 9 years) were tested on measures of phonological processing (phonological awareness, naming speed and verbal short-term memory) and reading. The results indicated that the children with DD performed significantly poorer in all measures compared with the CA and RL. Phonological awareness and naming speed showed a high accuracy (receiver operating characteristics curve analysis) for discriminating the children with DD from the CA and RL, whereas the presence of abnormally low scores in phonological awareness and naming speed were more frequent in the DD group than in the controls and the normative population. Hierarchical linear regression analyses revealed that phonological awareness was the most important predictor of all reading accuracy measures, whereas naming speed was particularly related to text reading fluency.
\end{abstract}

Keywords: Developmental dyslexia; phonological awareness; naming speed; verbal short-term memory; reading. 


\section{Introduction}

There is a strong consensus on the importance of phonological processing for reading development (bidirectional link) and it is widely accepted that the central difficulty in developmental dyslexia (DD) reflects a deficit in the phonological domain (Fletcher, 2009; Ramus, Marshall, Rosen, \& van der Lely, 2013; Vellutino, Fletcher, Snowling, \& Scanlon, 2004). The phonological domain deficits hypothesis is supported by neuroimaging studies, which have documented the disruption of neural systems for reading in individuals with DD, in particular, the left hemisphere posterior brain systems (Finn et al., 2014; Richlan, Kronbichler, \& Wimmer, 2011; Shaywitz, Lyon, \& Shaywitz, 2006). Although, the phonological domain is the main factor associated to reading performance, its weight varies as a function of script transparency (Caravolas, Lervåg, Defior, Málková, \& Hulme, 2013; Ziegler et al., 2010). Therefore, the present study examined the presence of specific deficits in the phonological processing of children with DD who were native speakers of an orthography of intermediate depth (European Portuguese orthography) and their association with reading fluency and reading accuracy. We also investigated the diagnostic accuracy of phonological processing measures to correctly discriminate between typical readers and children with DD.

Phonological processing is generally defined as the perception, storage, retrieval, and manipulation of the sounds of language during the acquisition, comprehension, and production of both spoken and written codes (Catts, Fey, Zhang, \& Tomblin, 1999). Phonological processing includes three interrelated but distinct phonological processes: (1) phonological awareness (PA), (2) phonological recoding in lexical access (also named naming speed, rapid naming or the lexical retrieval of phonological codes), and (3) phonetic recoding to maintain information in working memory [also named phonological memory or verbal short-term memory (VSTM)] (Torgesen, Wagner, \& Rashotte, 1994; Wagner \& Torgesen, 1987). Originally, these three phonological processes were treated as a single phonological component; however, the double-deficit hypothesis postulates that naming speed constitutes a second core 
deficit in DD that is independent from a phonological deficit (Wolf \& Bowers, 1999, 2000). The double-deficit hypothesis assumes that the naming speed uniquely contributes to the reading performance and that a subgroup of individuals with DD with naming speed problems in the absence of PA problems (and vice versa) should exist. Individuals with a double deficit will show more severe reading problems compared with individuals with a single naming or single phonological deficit because the two problems are independent and additive. Whereas some studies support the double-deficit hypothesis (Araújo, Pacheco, Faísca, Petersson, \& Reis, 2010; Sunseth \& Greig Bowers, 2002; Wolf, Bowers, \& Biddle, 2000), others did not find empirical evidence (Ackerman, Holloway, Youngdahl, \& Dykman, 2001; Pennington, Cardoso-Martins, Green, \& Lefly, 2001; Vaessen, Gerretsen, \& Blomert, 2009; Vukovic \& Siegel, 2006).

PA refers to the ability to perceive and manipulate the sounds of spoken words, which is typically measured by tasks that require the ability to discriminate and manipulate syllables or phonemes in words (e.g., deletion, substitution, blending, reversal, segmentation, and other tasks). There is strong evidence of the importance of PA in the acquisition of early reading skills across all alphabetic orthographies. This link appears to be bidirectional. Thus, PA facilitates reading development, and successful reading development improves PA performance (Boets et al., 2010; Perfetti, Beck, Bell, \& Hughes, 1987; Wagner, Torgesen, \& Rashotte, 1994). Children who are relatively strong in PA before reading instruction begins typically learn to read easier than other children, whereas children who exhibited impairments in PA tend to present significant difficulties in reading achievement (Catts et al., 1999; Nithart et al., 2011; Wagner \& Torgesen, 1987). Some of these children are eventually diagnosed with DD during the elementary school grades (Scarborough, 1990). Deficits in PA, relative to chronological-agematched controls (CA) and/or reading-level-matched controls (RL), have been found in various studies of DD in transparent and opaque orthographies (Boets et al., 2010; Caravolas, Volín, \& Hulme, 2005; Martin et al., 2010; Pennington et al., 2001). 
Phonological recoding in lexical access refers to the rapid access of phonological information stored in long-term memory, and it is usually assessed by naming speed tests. Denckla and Rudel (1976a, 1976b) found that children with DD are significantly slower in naming a set of well-known visual items (letters, numbers, colors, or objects) than typically developing children, and the authors named these tasks as "Rapid Automatized Naming" (RAN). A wide range of cognitive processes are involved in RAN tasks: integration of visual features and pattern information with stored orthographic representations, integration of visual and orthographic information with stored phonological representations, access and retrieval of phonological labels, attentional processes to the stimulus, processing speed, among others (for a review see: Kirby, Georgiou, Martinussen, \& Parrila, 2010; Norton \& Wolf, 2012). Several studies have suggested that children with DD have significant difficulties in RAN tasks because these tasks can be viewed as an index of how well children are able to establish the wordspecific orthographic representations that underlie reading (Clarke, Hulme, \& Snowling, 2005; Ehri, 1995). Even in orthographies that are more regular than English, individuals with DD manifest RAN deficits compared with $\mathrm{CA}$ and/or RL, which suggests that the vulnerability extends beyond phonological decoding. These findings have been reported for Dutch (Boets et al., 2010; de Jong \& van der Leij, 2003), French (Martin et al., 2010), German (Landerl, 2001), Portuguese (Araújo et al., 2010), Spanish (Jiménez, Rodríguez, \& Ramírez, 2009), and other languages. A large number of studies have consistently found that RAN ability is the most relevant predictor of reading fluency across all orthographies in typical and dyslexic readers (Kirby et al., 2010; Norton \& Wolf, 2012). Some authors have noted that in transparent orthographies, PA may be a less reliable marker of DD than RAN, most likely because the phonological demands are reduced in transparent orthographies (de Jong \& van der Leij, 2003; Snowling, 2006). Indeed, it is expected that children in more transparent orthographies experience less reading decoding (accuracy) problems, due to the more consistent graphemephoneme correspondence rules, than their peers of less transparent orthographies, leaving 
fluency as the most useful reading variable (Davies, Rodríguez-Ferreiro, Suárez, \& Cuetos, 2013; Jiménez et al., 2009; Ziegler et al., 2010). On the other hand, some studies have also found that RAN is a better long-term predictor of reading performance (e.g., reading accuracy, word recognition and/or reading comprehension) in transparent (Norwegian and Swedish: Furnes \& Samuelsson, 2010) and opaque orthographies (English: Kirby, Parrila, \& Pfeiffer, 2003), whereas PA appears to be most strongly related to the early stages of reading development.

The phonetic recoding to maintain information in working memory or VSTM refers to the ability to recode and maintain verbal information in a sound-based representational system. This ability is typically assessed by tasks that require the temporary storage of verbal items, such as digit span, words, pseudowords or nonwords repetition tasks. The temporary storage of material that has been read is dependent on working memory (Baddeley, 2003), which takes into account the storage of items for later retrieval and the demands of the partial storage of information related to several levels of text processing (Swanson, 1999). A large number of studies have found that children with DD perform significantly lower in VSTM tasks than typically developing children, which suggests that they have deficits at least in the phonological loop of Baddeley's working memory model (Everatt, Weeks, \& Brooks, 2008; Kibby \& Cohen, 2008; Moura, Simões, \& Pereira, 2014).

Recent cross-linguistic studies have supported the hypothesis that PA is the best predictor of reading development in transparent and opaque orthographies in typically developing children (Caravolas et al., 2013; Furnes \& Samuelsson, 2009; Vaessen et al., 2010; Ziegler et al., 2010). For example, Ziegler et al. (2010) found that PA was the main factor associated with reading accuracy and reading fluency across the five languages studied (Finnish, Hungarian, Dutch, Portuguese and French), and its impact was found to be modulated by the transparency of the orthography (PA is a stronger predictor in less transparent orthographies). The influence of RAN was limited to reading fluency, and VSTM showed some predictive value for reading 
accuracy only in Finnish and Hungarian orthographies. Note that, Ziegler et al. (2010) used sequential naming of pictured objects and there is evidence that alphanumeric RAN stimuli (e.g., letters or numbers) often lead to higher correlations with reading than do nonalphanumeric RAN stimuli (e.g., colors or objects) (Kirby et al., 2010). In this case, the use of a non-alphanumeric RAN stimulus may explain the atypically (low) relationship between RAN and reading. Similarly, Vaessen et al. (2010) confirmed that cognitive mechanisms underlying reading fluency of different word types were similar across the three alphabetic orthographies studied (Hungarian, Dutch and Portuguese). The authors also found that the association of reading fluency with PA (but not with RAN or VSTM) was modulated by orthographic complexity and the contribution of PA decreased as a function of grade, whereas the contribution of RAN increased.

The same pattern has also been observed in DD samples. Ackerman and colleagues (2001) found that English-speaking children with DD performed significantly worse than typical readers in the PA and RAN tasks and that PA was the best predictor of reading decoding and word recognition. In a Dutch longitudinal study, Boets et al. (2010) also found that children with DD scored significantly lower than controls in the PA, RAN and VSTM tasks. They further demonstrated through hierarchical regression analyses that PA was more strongly related to reading accuracy and that RAN was more strongly related to reading fluency, whereas VSTM only contributed to a small proportion of the unique variance in reading accuracy. The results from a Portuguese study showed that children with DD scored significantly lower than typically developing children on PA and RAN and that PA predicted reading fluency for both groups, whereas RAN only predicted reading fluency for the DD group (Araújo et al., 2010).

Although the association between phonological processing and reading performance is very well documented in the literature, the diagnostic accuracy of phonological processing measures to correctly discriminate between children with DD and typical developing children is clearly less explored. Recently, Landerl et al. (2013) investigated the relationship between 
phonological processing and diagnostic accuracy in children with DD and CA (did not include a RL group) speaking six different languages spanning a large range of orthographic complexities (Finnish, Hungarian, German, Dutch, French, and English). They concluded that PA, RAN and VSTM were reliable predictors of DD status (odds ratio of $0.354,0.356$ and 0.694 , respectively). They also found that PA and RAN were stronger concurrent predictors in complex (odds ratio of 0.187 and 0.262 , respectively) than in less complex orthographies (odds ratio of 0.481 and 0.491 , respectively), with an area-under-the-curve (AUC) of the predictive model of $.817, .877$ and .929 for low, medium and high orthographic complexity languages.

In summary, the extensive body of research with school-age children has shown that: (1) children with DD showed severe impairments in phonological processing; (2) PA and RAN tend to be the strongest predictors of reading in children with DD and typical readers (specific patterns can be observed as a function of the orthographic depth); and (3) PA is the best predictor of reading accuracy, whereas RAN is more related to reading fluency.

The level of orthographic consistency is the key factor determining the rate of reading acquisition across different languages and might influence how DD is manifested. Studying the subcomponents of reading across languages helps researchers to understand what factors are universal and which are language or orthography-specific factors in the reading system (Norton $\&$ Wolf, 2012). The few Portuguese studies that have explored the presence of phonological processing deficits in children with DD rarely included a RL group (some exceptions: Araújo et al., 2011; Sucena, Castro, \& Seymour, 2009) or investigated the role of VSTM on reading performance (some exceptions: Moura et al., 2014; Silva, Silva, \& Martins, 2014). Similarly, few studies have explored the accuracy of phonological processing measures to correctly discriminate between typical (CA and RL) and dyslexic readers (some exceptions: Landerl et al., 2013). Therefore, the present study has three main objectives: (1) to examine the presence of deficits in the phonological domain and in the reading performance of Portuguese-speaking children with DD; (2) to analyze the diagnostic accuracy of phonological processing measures to 
correctly discriminate between typical readers (CA and RL) and children with DD through a receiver operating characteristics (ROC) curve analysis and an abnormal low scores analysis; and (3) to determine the predictive effect of phonological processing on reading fluency and reading accuracy. Based on the existing literature, we expected that Portuguese children with DD would show significant impairments in all phonological processes and would reveal significant difficulties in reading fluency and accuracy (particularly in the reading of irregular words and pseudowords). We also expected that phonological processing would be an accurate measure for discriminating children with DD from CA and RL. Finally, we expected that PA would be the most significant predictor of reading accuracy in the Portuguese orthography, whereas RAN would be more related to reading fluency.

The European Portuguese orthography is considered to be an intermediate depth (Seymour, Aro, \& Erskine, 2003; Sucena et al., 2009). Seymour et al. (2003) examined the beginning of reading acquisition in 13 European orthographies and found that children become fluent and accurate before the end of the first grade. The exceptions to this development pattern were English, French, Danish and Portuguese (the Portuguese and French orthographic code learning trajectories were quite similar). They found that reading accuracy in most transparent orthographies generally reaches a ceiling effect at the end of the first grade, which contrasts with the reading accuracy found in orthographies of intermediate depth (e.g., Portuguese children read correctly approximately $74 \%$ of words and $77 \%$ of non-words) or in an opaque orthography (English children read correctly approximately 34\% of words and 29\% of non-words). They concluded that learning to read in the European Portuguese orthography proceeded less rapidly than in transparent orthographies, such as German, Greek, Italian or Finnish, but more rapidly than English.

Fernandes, Ventura, Querido, and Morais (2008) investigated the initial development of reading and spelling in the European Portuguese orthography and concluded that Portuguese children rely on grapheme-phoneme conversion at the initial stages of literacy acquisition [a 
regularity effect (i.e., the superiority of regular words over irregular words) was present in both reading and spelling by the middle of the first grade]. By the end of the first grade, the children had acquired some knowledge of the lexical orthographic representation [a lexicality effect (i.e., the superiority of words over pseudowords) was found in spelling]. Several orthographic and phonemic features concur which characterize European Portuguese orthography as an intermediate depth; for example, the use of grapheme-phoneme correspondence rules is particularly difficult (e.g., there are five vowel letters for 18 vocalic phonemes).

Sucena et al. (2009, p. 794) stated "dyslexia in Portuguese should conform more to the English model than to the German model”. Indeed, previous Portuguese studies found a lexicality effect in typical and dyslexic readers (Araújo, Faísca, Bramão, Petersson, \& Reis, 2014; Sucena et al., 2009), and a stronger contribution of PA to reading performance (Araújo et al., 2010; Sucena et al., 2009), which is more consistent with the results from less transparent orthographies. For additional information about the characteristics of the European Portuguese orthography, see: Albuquerque (2012), Fernandes et al. (2008) and Sucena et al. (2009).

\section{Method}

\section{Participants}

The participants were 72 Portuguese children with a mean age of 10.18 years $(S D=1.42)$. The DD group ( $N=24$; aged 10 to 12 years) included $79 \%$ male and $21 \%$ female, with a mean age of 11.04 years $(S D=0.86)$. The children with DD were in the $4^{\text {th }}$ to $6^{\text {th }}$ grades, and $36 \%$ were included in the special education system. The DD group was compared with two matched control groups: the CA and the RL. In the CA group ( $N=24$; aged 10 to 12 years), $67 \%$ were male and $33 \%$ were female, with a mean age of 11.00 years $(S D=0.83)$; the children were in the $4^{\text {th }}$ to $6^{\text {th }}$ grades. The CA group was matched for age $\chi^{2}(2)=0.125, p=.939$, with the DD group, yielding non-significant differences in gender $\chi^{2}(1)=0.949, p=.330$ and grade $\chi^{2}(2)=$ $2.427, p=.297$. The RL group $(N=24$; aged 7 to 9 years $)$ included $58 \%$ male and $42 \%$ female, 
with a mean age of 8.49 years $(S D=0.58)$; the children were in the $2^{\text {nd }}, 3^{\text {rd }}$ and $4^{\text {th }}$ grades. The RL group $(M=59.27 \pm 8.95)$ was matched on reading text fluency $t(46)=0.577, p=.567, d=$ 0.16 , with the DD group $(M=56.59 \pm 20.88)$, yielding non-significant differences in gender $\chi^{2}(1)=2.424, p=.119$. The $\mathrm{RL}$ group was matched with a reading text fluency measure ("O Rei"; Carvalho \& Pereira, 2009) because in less opaque orthographies, the reading text accuracy has tended to reach a ceiling effect after the first years of school attendance (Seymour et al., 2003).

Inclusion criteria. For the three reading groups, only children who met the following criteria were included: (1) Wechsler Intelligence Scale for Children - Third Edition - Full Scale IQ (WISC-III FSIQ) $\geq 90$; (2) native speakers of European Portuguese; (3) absence of a visual, hearing or motor handicap; (4) exclusion of a language impairment, emotional disturbance, dyscalculia, disruptive behavior disorder (attention deficit hyperactivity disorder, oppositional defiant disorder and conduct disorder), neurological impairment or other psychiatric disorders. For the CA and RL groups, the children with special educational needs were also excluded.

In the DD group, only children who were previously diagnosed with DD by a psychologist, child psychiatrist, developmental pediatrician or a child neurologist and who simultaneously had a score less than or equal to the $15^{\text {th }}$ percentile in a reading fluency and accuracy test administered during the testing session were included. These cutoff score criteria (WISC-III FSIQ $\geq 90$ and both reading fluency and accuracy measures $\leq 15^{\text {th }}$ percentile) are similar to, and in some cases stricter than, the inclusion criteria used in previous studies (e.g., Frijters et al., 2011; Reiter, Tucha, \& Lange, 2005; Swanson, 1999, 2011). For the CA and RL groups, only children with a score greater than the $40^{\text {th }}$ percentile on both reading measures were included.

\section{Measures and Procedures}


Intellectual ability. The Portuguese version of the WISC-III (Wechsler, 2003) was administered to measure general intellectual ability. The WISC-III FSIQ scores $(M=100 ; S D=$ 15) were analyzed and used as a covariate in the inferential analysis. The factor structure of the Portuguese version of the WISC-III, analyzed through an exploratory and confirmatory factor analysis, yielded adequate psychometric properties for a two-factor model (Verbal IQ and Performance IQ) and for a three-factor model (Verbal Comprehension, Perceptual Organization and Processing Speed).

Phonological awareness. The Phonological Awareness subtest of the Coimbra Neuropsychological Assessment Battery (BANC; Simões et al., in press) was used to assess PA and comprises two tasks. In the Deletion task (20 items), the child was asked to delete a particular phoneme on familiar words (e.g., say sopa [sope] without the se [s]). In the Substitution task (20 items), the child was asked to replace one or more phonemes for other(s) phoneme(s) on familiar words (e.g., say judo [3udu] but replace the je [3] to xe [S]). For both PA tasks, the raw scores (number of correct responses) were converted to scaled scores $(M=10, S D$ =3) based on age-specific norms. The reliability of the BANC normative sample for the Deletion task had a Cronbach's alpha $=.91$ and a test-retest $=.83$, whereas the Substitution task had a Cronbach's alpha $=.90$ and a test-retest $=.85$.

Naming speed. The RAN (Numbers) task of the BANC was used to examine phonological access to lexical storage. The child was asked to name as quickly as possible 50 visual stimuli (numbers 2, 4, 6, 7 and 9) randomly displayed on a card in a 10x5 matrix. The raw scores (amount of time, in seconds, required to complete the task) were converted to scaled scores $(M=10, S D=3)$ based on age-specific norms. The reliability of the BANC normative sample for the RAN task was obtained through test-retest $(r=.78)$.

Verbal short-term memory. The Forward task from the Digit Span (FDS) subtest of the WISC-III was used to assess VSTM. This task required that the child correctly repeat a series of digits in the order in which they were read to him/her. One point per trial (raw score) was given 
for a correct repetition. To control for the influence of age on the results of the FDS, an ageadjusted score was created by regressing the FDS onto age and then saving the unstandardized residual score (the Portuguese version of the WISC-III only provides age-scaled scores for the Digit Span subtest with both forward and backward tasks). The reliability (split-half) of the Digit Span subtest was .80.

Reading text fluency and accuracy. The "O Rei" ("The King"; Carvalho \& Pereira, 2009) is a three-minute reading test that measures the reading fluency (the number of correctly read words in one minute) and the reading accuracy (the percentage of correctly read words) of a Portuguese traditional tale for children from $1^{\text {st }}$ to $6^{\text {th }}$ grade. The test-retest from the normative sample was $r=.94$ for reading fluency and $r=.80$ for reading accuracy.

Reading words. To assess the reading accuracy of individual words, we used the Oral Reading (PAL-PORT 22) subtest from the Portuguese version (Festas, Martins, \& Leitão, 2007) of the Psycholinguistic Assessment of Language (PAL; Caplan, 1992). The PAL-PORT 22 comprises 146 words (48 regular, 47 irregular and 51 pseudowords). Based on previous studies that used the PAL-POR 22 with typically developing children, we selected 40 words: 16 regular (8 high-frequency and 8 low-frequency words; e.g., sardinha [ser' $\delta$ ine], rusga ['Ruzye]), 16 irregular (8 high-frequency and 8 low-frequency words; e.g., fluxo ['fluksu], exotismo

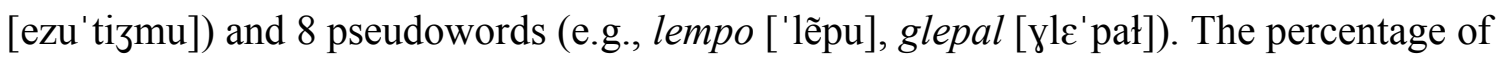
correctly read words was calculated for the regular, irregular and pseudowords. The reliability (Cronbach's alpha) of the PAL-PORT 22 was .75.

The administration of these tests was included as part of a broad neuropsychological research that was also comprised of other measures (e.g., working memory, executive functions and others). Each child completed two individual sessions (separated by an interval of 10 to 15 days), which lasted approximately 90 minutes per session in a clinic or school setting during a weekday. All tests were administered in a fixed order. No incentives were offered in exchange for participation. 


\section{Statistical Analyses}

Statistical analyses were performed using IBM SPSS Statistics 19. Group differences were analyzed using multivariate analyses of covariance (MANCOVA) with the WISC-III FSIQ as a covariate because significant group differences $(\mathrm{CA}=107.25 \pm 12.88 ; \mathrm{RL}=110.79 \pm 12.47$; $\mathrm{DD}=96.67 \pm 8.55)$ were observed, $F(2,69)=9.853, p<.001, \eta^{2}{ }_{\mathrm{p}}=.22(\mathrm{CA}=\mathrm{RL}>\mathrm{DD})$. If the multivariate analysis indicated a significant overall difference $(p<.05)$, then a univariate test was applied to determine which dependent variables were responsible for the multivariate difference. Post hoc comparisons were conducted with the Bonferroni correction for multiple comparisons. In specific cases, repeated measures ANOVAs were also used. Partial eta-squared $\left(\eta^{2}\right)$ were additionally calculated to determine the effect size of the differences between the groups.

A ROC curve analysis was performed to examine the accuracy of phonological processing measures to discriminate children with DD from CA and RL. A ROC curve analysis systematically sweeps across all possible true positive (sensitivity) and false positive (1specificity) values of a diagnostic test. That is, sensitivity and specificity are determined for each cut-off point. The ROC curve analysis graphically illustrates the test's full range of diagnostic utility and can be used to calculate the AUC, which provides an accuracy index of the test (Fawcett, 2006). The more accurately a test is able to discriminate between groups, the more its ROC curve will deviate toward the upper left corner of the graph. The AUC is the average of the true positive rate, taken uniformly over all possible false positive rates (Krzanowski \& Hand, 2009) that range between .5 and 1.0. An AUC value of 1.0 is perfectly accurate because the sensitivity is 1.0 when the false positive rate is .0, whereas an AUC value of .5 reflects a completely random classifier. An AUC of .5 to .7 indicates a low test accuracy, .7 to .9 a moderate accuracy and .9 to 1.0 a high accuracy (Swets, 1988). 


\section{Results}

\section{Correlational Analysis}

Table 1 shows the Pearson correlation coefficients between general intellectual ability, phonological processing and reading measures. The WISC-III FSIQ showed small to moderate positive correlations with phonological processing and reading measures. Strong correlations were observed between PA tasks and RAN. In general, PA and RAN were highly correlated with reading.

(Table 1 about here)

\section{Phonological Processing: Group Differences}

A MANCOVA was performed with phonological processes as dependent variables, reading group (CA, RL and DD) as fixed factor and WISC-III FSIQ as a covariate. The reading group had a significant main effect, $F(8,130)=13.865, p<.001$, Wilks' $\Lambda=.29, \eta_{\mathrm{p}}^{2}=.46$. Univariate tests revealed that the children with DD scored significantly lower than the CA and the RL in the PA Deletion, $F(2,68)=49.458, p<.001, \eta^{2} \mathrm{p}=.59$; PA Substitution, $F(2,68)=$ $30.140, p<.001, \eta^{2}=.47 ;$ RAN, $F(2,68)=25.896, p<.001, \eta^{2}{ }_{p}=.43$; and FDS, $F(2,68)=$ $8.111, p<.01, \eta^{2} \mathrm{p}=.19($ see Table 2$)$.

(Table 2 about here)

\section{Reading: Group Differences}

A MANCOVA with reading group (CA, RL and DD) as fixed factor and WISC-III FSIQ as a covariate showed statistically significant differences in reading text, $F(4,134)=19.820, p<$ .001 , Wilks' $\Lambda=.40, \eta_{\mathrm{p}}^{2}=.37$, and in reading words, $F(6,132)=12.774, p<.001$, Wilks' $\Lambda=$ $.40, \eta^{2} \mathrm{p}=.36$. The univariate statistics yielded a significant effect in text reading fluency, $F(2$, 
$68)=32.773, p<.001, \eta_{\mathrm{p}}^{2}=.49$, and accuracy, $F(2,68)=13.897, p<.001, \eta_{\mathrm{p}}^{2}=.29$, as well as in reading regular words, $F(2,68)=20.595, p<.001, \eta_{\mathrm{p}}^{2}=.38$, irregular words, $F(2,68)=$ 17.911, $p<.001, \eta_{\mathrm{p}}^{2}=.34$, and pseudowords, $F(2,68)=27.335, p<.001, \eta_{\mathrm{p}}^{2}=.45$. As shown in Table 2, the CA outperformed the children with DD in all reading measures. Compared with the RL, the children with DD scored significantly lower in text reading accuracy and in reading regular, irregular and pseudowords but a non-significant difference was found in text reading fluency (as expected because this measure was used to match children with DD to RL).

In addition, we performed two repeated measures ANOVAs to analyze the presence of a lexicality effect (regular words $>$ pseudowords) and a regularity effect (regular words $>$ irregular words). A repeated measures ANOVA with lexicality effect (regular vs. pseudoword) as withinsubjects factor and reading group (CA vs. RL vs. DD) as between-subjects factor yielded a significant main effect for lexicality, $F(1,69)=29.142, p<.001, \eta^{2}{ }_{p}=.29$ and for the interaction between lexicality and reading group, $F(2,69)=12.537, p<.001, \eta^{2}{ }_{p}=.26$. This main effect indicates that regular words were read more accurately than pseudowords, whereas the significant interaction occurred because the magnitude of the lexicality effect was stronger for the children with DD (19.01\% advantage) than the CA (9.11\% advantage) and the RL ($1.3 \%$ advantage). For the regularity effect, a repeated measures ANOVA contrasting reading groups (CA vs. RL vs. DD) revealed a significant effect for regularity, $F(1,69)=112.533, p<$ $.001, \eta^{2}{ }_{p}=.62$, but the interaction did not reach significance, $F(2,69)=0.060, p=.942, \eta^{2}{ }_{p}=$ .00 . This main effect indicates that regular words were read more accurately than irregular words, whereas the non-significant interaction was because the magnitude of the regularity effect was homogeneous between the groups $(\mathrm{CA}=14.32 \%$ advantage, $\mathrm{RL}=15.37 \%$ advantage, and children with $\mathrm{DD}=15.37 \%$ advantage).

\section{Phonological Processing: Diagnostic Accuracy and Abnormally Low Scores}


Although the results from the inferential analyses showed significant group differences in the phonological processing, it does not imply that PA, RAN and FDS tasks can correctly discriminate the children with DD from the CA and RL. Therefore, a ROC curve analysis was performed for the CA versus DD and the RL versus DD separately. The more accurately a task discriminates between the groups, the higher the AUC value. As shown in Table 3, all phonological processing measures were significant variables for discriminating between the subjects with a moderate to high diagnostic accuracy. The PA Deletion task revealed a higher level of accuracy to correctly discriminate the children with DD from the CA (AUC $=.980)$ and the RL $(A U C=.957)$. Thus, a randomly selected child with DD will have a lower score on the PA Deletion task approximately $98.0 \%$ and $95.7 \%$ of the time compared with a randomly selected child from the CA and the RL groups, respectively.

In addition, we computed a pairwise comparison of AUC values in order to analyze the presence of significant differences between PA, RAN and FDS. The comparison was performed using MedCalc 12.7. For the CA versus DD, a significant difference was observed for: PA Deletion $>$ FDS $(z=2.615, p<.01)$ and PA Substitution $>$ FDS $(z=2.504, p<.05)$. Similarly, for the RL versus DD, a significant difference was observed for: PA Deletion $>$ FDS $(z=2.865$, $p<.01)$ and PA Substitution $>$ FDS $(z=2.049, p<.05)$.

(Table 3 about here)

Analyzing the abnormally low scores in the PA Deletion, PA Substitution and RAN tasks, we found that $41.7 \%$ of the children with DD exhibited an age-scaled score $<7(z<-1)$, and $16.7 \%$ of the children exhibited an age-scaled score $<4(z<-2)$ in these three tasks simultaneously. No cases were identified in the CA and RL groups for either cutoff score. To determine the degree of abnormality of these profiles (these three subtests with a $z<-1$ or with a $z<-2)$ in the normative population, we used the Crawford, Garthwaite and Gault (2007) method 
and software. Using the BANC standardization sample ( $N=1104$ children aged 5 to 15 years), we computed the estimated percentage of the healthy population that is expected to exhibit these abnormally low scores. Only $1.87 \%$ of the normative population exhibited an age-scaled score $<$ 7, and only $0.02 \%$ exhibited an age-scaled score $<4$ in these three subtests, which is in contrast to the higher percentage observed in our DD group.

\section{Predictive Effect of Phonological Processing in Reading}

To determine the predictive effect of phonological processing on reading ability, a series of hierarchical linear regression analyses were conducted for each of the dependent variable. For PA, a composite score was computed because the PA Deletion and the PA Substitution were highly correlated $(r=.812, p<.001)$. The scores of all measures entered in the regression analysis were converted to $z$-scores to minimize the possible impact of different variable scaling. The predictive variables were entered in the following order: age (covariate) was entered into the first block, and PA, RAN and FDS were entered into the second block. Table 4 shows the variance $\left(R^{2}\right.$ and $\left.\Delta R^{2}\right)$ of the regression model, the standardized regression coefficient $(\beta)$, the ttest and the squared part correlation $\left(p r^{2}\right)$ for each of the four predictor variables (age, PA, RAN and FDS) on each reading task. The $p r^{2}$ represents the unique variance of each predictor when the overlapping linear effects of all other predictive variables were statistically removed.

For text reading fluency, PA and RAN were significant predictors, with RAN showing the highest unique variance (explained $11.4 \%$ of the variance after controlling for age, PA and FDS) and the highest standardized regression coefficient, whereas the regression model explained $71.2 \%$ of the total variance. For text reading accuracy, only PA and RAN showed a significant predictive effect, with a unique variance of $10 \%$ and $9.7 \%$, respectively, whereas the regression model explained $55.8 \%$ of the total variance. A large amount of shared variance was observed.

The results for the three reading words outcomes were very similar. Only PA exhibited significant standardized regression coefficients for all tasks and explained for more than $15 \%$ of 
the unique variance and RAN was a significant predictor for regular and irregular words. Nonsignificant standardized regression coefficients were found for FDS. The four predictor variables explained between 51.9\% (irregular words) and $61.4 \%$ (regular words) of the total variance.

(Table 4 about here)

\section{Discussion}

There is extensive empirical evidence indicating that deficits in phonological processing are among the most prominent characteristics of children with DD, and it is also well-known that the level of orthographic consistency may influence how DD is manifested. The European Portuguese language is considered an orthography of intermediate depth (Sucena et al., 2009); it is more transparent than English, French and Danish, but less regular than Spanish, Italian, Greek, German and Finnish (Seymour et al., 2003).

The first aim of the present study was to investigate the specificity of phonological processing and reading deficits in Portuguese children with DD. The results from the inferential analyses revealed that the children with DD showed significantly lower scores than the CA and the RL in the PA Deletion, PA Substitution, RAN and FDS measures with very large effect sizes. These findings revealed that the ability to perceive and manipulate the sounds of spoken words, the rapid access of phonological information stored in the mental lexicon and the ability to code information phonologically for temporary storage in working memory were significantly impaired in the Portuguese children with DD, which is consistent with other studies from different orthographies (Boets et al., 2010; Everatt et al., 2008; Jiménez et al., 2009; Willburger, Fussenegger, Moll, Wood, \& Landerl, 2008).

As expected, the Portuguese-speaking children with DD showed a severe impairment in all reading accuracy measures, suggesting a developmental deficit (CA and RL $>$ DD). The 
children with DD exhibited specific difficulties in reading pseudowords (57.81\% accuracy), which is consistent with studies from less transparent orthographies that have shown significant deficits in the phonological decoding strategy because grapheme-phoneme correspondence rules are considerably more complex. Indeed, studies with German-speaking (Wimmer, Mayringer, \& Landerl, 2000) and Spanish-speaking (Davies et al., 2013) children have shown that the nonword reading accuracy in children with DD approaches normal performance, which is in contrast to studies with English-speaking children (for a review, see: Herrmann, Matyas, \& Pratt, 2006). A lexicality effect and a regularity effect were also observed, that is, regular words were read more accurately than pseudowords and irregular words, respectively. The dual-route theories (Baron \& Strawson, 1976; Coltheart, 1978, 2005) postulate two different ways in which readers can read differently written words: (1) the lexical route (also called the orthographic route) - regular and irregular words can be recognized directly by accessing a representation of their orthographic form in an internal lexicon; and (2) the sublexical route (also called the phonological route) - the reading of regular words and nonwords involves the use of graphemephoneme correspondence rules. During word recognition, these two processes work separately and simultaneously: the reading of irregular words requires accessing a lexicon or memory store of previously seen written words (the use of the sublexical route to read an irregular word yields a "regularization error"), the reading of nonwords requires the use of grapheme-phoneme correspondence rules, whereas for regular words, both lexical and sublexical routes generate the correct pronunciation (Castles, 2006; Coltheart, 2005; Cortese \& Simpson, 2000). Thus, the reading of irregular words and pseudowords may be less accurate and may have a longer latency time than reading regular words.

When the magnitude of the lexicality and the regularity effects between children with DD and typical readers (CA and RL) were compared, we found that a significant difference occurred for the lexicality effect, but not for the regularity effect. These results may suggest that the phonological decoding strategy is particularly compromised in these Portuguese children with 
DD. As Ziegler and Goswami (2005, p. 18) stated "phonological rather than orthographic deficits therefore appear to underlie developmental dyslexia in all languages so far studied. Children with dyslexia are not worse than RL children in gaining orthographic access to whole words. Rather, they are worse at computing sublexical phonology". Concerning to regularity effect, mixed results were found in orthographies of intermediate depth. Sprenger-Charolles, Colé, Kipffer-Piquard, Pinton and Billard (2009) also found that the difference between regular and irregular words was not greater for French-speaking children with DD compared to RL. A Portuguese study with children with DD ( $3^{\text {rd }}$ and $4^{\text {th }}$ grades $)$ showed a developmental delay (CA $>$ DD with $\mathrm{RL}=\mathrm{DD})$ in phonological decoding (lexicality effect) and a developmental deficit (CA and RL > DD) in orthographic processing (regularity effect) (Sucena et al., 2009). Note that, in the Sucena et al.'s study a ceiling effect was found for regular words in CA, RL and DD groups $(97.3 \%, 93.4 \%$ and $91.8 \%$, respectively), which may explain the difference with our findings. Furthermore, Araújo et al. (2014) found evidence that Portuguese children with DD were not as flexible as $\mathrm{CA}$ in switching from phonological decoding (sublexical) strategies to orthographic (lexical) strategies.

Another purpose of the present study was to analyze the accuracy of phonological processing measures in discriminating children with DD from CA and RL. Whereas the presence of a significant impairment in phonological processing measures in the children with DD has been extensively reported in the literature, few studies have explored the accuracy of these measures in differentiating between typical and dyslexic readers. In a recent crosslinguistic study with six different languages, Landerl et al. (2013) found that PA and RAN were strong predictors of DD (predictive power increases with orthographic complexity), while VSTM played a minor role. Our results from the ROC curve analysis also showed a moderate accuracy for VSTM and a high accuracy for PA and RAN in discriminating the children with DD from the CA and the RL. These findings support the relevance of both PA and RAN measures in the diagnostic assessment of DD in an orthography of intermediate depth. Similar to 
the Landerl et al. (2013) study, earlier assumptions that RAN might be a more reliable marker of DD than PA in less opaque orthographies were not supported by the current study. Taken together, the results from the inferential analysis and the ROC curve analysis showed that PA is the most reliable marker of DD in Portuguese-speaking children, followed by RAN. On the other hand, a higher incidence of abnormally low scores in PA and RAN tasks was observed for the children with DD when compared with the controls and the normative population. These results reinforce the findings from the inferential analysis regarding the significant impairments of PA and naming speed in DD.

The final purpose was to analyze the predictive effect of phonological processing in reading ability. The results showed that PA was the most important predictor for all reading tasks (except for text reading fluency) and RAN was particularly related to text reading fluency. These findings are convergent with previous studies that found that PA is mainly related to decoding accuracy (Boets et al., 2010; Pennington et al., 2001), whereas RAN is an important predictor of reading fluency (Savage \& Frederickson, 2005; Torppa, Georgiou, Salmi, Eklund, \& Lyytinen, 2012; Vaessen et al., 2009) independent of the transparency of the orthography. In addition, we also found that RAN explained unique variance in the reading of regular and irregular words, but its contribution was not significant for pseudowords. As noted previously, orthographic processing (lexical route) occurs when words are processed as single units rather than as a sequence of grapheme-phoneme correspondence rules. Therefore, because of the greater involvement of orthographic processing in the reading of regular and irregular words, our findings may suggest that RAN is more related to orthographic processing. Indeed, several authors have found that RAN is strongly related to irregular word reading (rather than pseudoword) and reading fluency (rather than accuracy) supporting the hypothesis that RAN is more associated to orthographic processing (Bowers, 1995; Bowers \& Ishaik, 2003; Bowers \& Newby-Clark, 2002; for a review, see Kirby et al., 2010). Relatively inconsistent findings have been reported regarding the predictive effect of VSTM. As in our study, Ziegler et al. (2010) 
found that VSTM did not make a unique contribution to reading fluency and accuracy after controlling for PA and RAN in the Dutch, French and Portuguese subsamples. In contrast, some studies of children with DD and/or typical developing children found that VSTM contribute to a small proportion of the unique variance in reading accuracy (Boets et al., 2010) or word reading fluency (Landerl \& Wimmer, 2008).

Notwithstanding the relevance of the present study, there are some limitations that should be addressed in future research. First, the inclusion of word reading latency time (or reaction time) measures is important because it has been hypothesized that latency time may be a more critical issue than reading accuracy in less opaque orthographies. Indeed, a ceiling effect was observed in the CA group in some reading accuracy measures, thus the additional inclusion of latency time measures would have been a better baseline to compare reading differences between groups. Second, some authors have suggested that less transparent orthographies would have a higher incidence of phonological dyslexia subtype (Castles \& Coltheart, 1993; Jiménez et al., 2009; Sprenger-Charolles, Colé, Lacert, \& Serniclaes, 2000). Children with the phonological dyslexia subtype revealed a selective deficit in the sublexical route and showed difficulties in the reading of nonwords (but not in irregular words), whereas children with the surface dyslexia subtype exhibited a selective deficit in the lexical route and showed difficulties in the reading of irregular words (but not in nonwords). Thus, it would also be particularly interesting to analyze the specific psycholinguistic characteristics of the phonological and surface dyslexia subtypes in the European Portuguese orthography and explore their prevalence.

In conclusion, phonological processing deficits were important characteristics of DD in Portuguese children. These results are consistent with the studies that indicated that PA is the most reliable marker of DD and the most important predictor of reading accuracy, whereas RAN was particularly related to text reading fluency, suggesting that the phonological processing role in reading ability may be relatively universal (at least in alphabetic languages). 


\section{References}

Ackerman, P. T., Holloway, C. A., Youngdahl, P. L., \& Dykman, R. A. (2001). The doubledeficit theory of reading disability does not fit all. Learning Disabilities Research \& Practice, 16(3), 152-160. doi: 10.1111/0938-8982.00016

Albuquerque, C. P. (2012). Rapid naming contributions to reading and writing acquisition of European Portuguese. Reading and Writing, 25(4), 775-797. doi: 10.1007/s11145-011$9299-6$

Araújo, S., Faísca, L., Bramão, I., Petersson, K. M., \& Reis, A. (2014). Lexical and phonological processes in dyslexic readers: Evidence from a visual lexical decision task. Dyslexia, 20(1), 38-53. doi: 10.1002/dys.1461

Araújo, S., Inácio, F., Francisco, A., Faísca, L., Petersson, K. M., \& Reis, A. (2011). Component processes subserving rapid automatized naming in dyslexic and non-dyslexic readers. Dyslexia, 17(3), 242-255. doi: 10.1002/dys.433

Araújo, S., Pacheco, A., Faísca, L., Petersson, K. M., \& Reis, A. (2010). Visual rapid naming and phonological abilities: Different subtypes in dyslexic children. International Journal of Psychology, 45(6), 443-452. doi: 10.1080/00207594.2010.499949

Baddeley, A. (2003). Working memory: Looking back and looking forward. Neuroscience, 4(10), 829-839. doi: 10.1038/nrn1201

Baron, J., \& Strawson, C. (1976). Use of orthographic and word-specific knowledge in reading words aloud. Journal of Experimental Psychology: Human Perception and Performance, 2(3), 386-393. doi: 10.1037/0096-1523.2.3.386

Boets, B., de Smedt, B., Cleuren, L., Vandewalle, E., Wouters, J., \& Ghesquière, P. (2010). Towards a further characterization of phonological and literacy problems in Dutchspeaking children with dyslexia. British Journal of Developmental Psychology, 28(1), 531. doi: $10.1348 / 026151010 \times 485223$ 
Bowers, P. G. (1995). Tracing symbol naming speed's unique contributions to reading disabilities over time. Reading and Writing, 7(2), 189-216. doi: 10.1007/BF01027185

Bowers, P. G., \& Ishaik, G. (2003). RAN's contribution to understanding reading disabilities. In H. L. Swanson, K. R. Harris \& S. Graham (Eds.), Handbook of learning disabilities (pp. 140-157). New York: Guilford.

Bowers, P. G., \& Newby-Clark, E. (2002). The role of naming speed within a model of reading acquisition. Reading and Writing, 15(1-2), 109-126. doi: 10.1023/A:1013820421199

Caplan, D. (1992). Language: Structure, processing, and disorders. Cambridge, MA: The MIT Press.

Caravolas, M., Lervåg, A., Defior, S., Málková, G. S., \& Hulme, C. (2013). Different patterns, but equivalent predictors, of growth in reading in consistent and inconsistent orthographies. Psychological Science, 24(8), 1398-1407. doi:

$10.1177 / 0956797612473122$

Caravolas, M., Volín, J., \& Hulme, C. (2005). Phoneme awareness is a key component of alphabetic literacy skills in consistent and inconsistent orthographies: Evidence from Czech and English children. Journal of Experimental Child Psychology, 92(2), 107-139. doi: 10.1016/j.jecp.2005.04.003

Carvalho, A., \& Pereira, M. (2009). O Rei - Um teste para avaliação da fluência e precisão da leitura no $1^{\circ}$ e $2^{\circ}$ ciclos do Ensino Básico [The King - Assessment test of the reading fluency and precision in the first and second cycles of elementary school]. Psychologica, $51,283-305$.

Castles, A. (2006). The dual route model and the developmental dyslexias. London Review of Education, 4(1), 49-61. doi: 10.1080/13603110600574454

Castles, A., \& Coltheart, M. (1993). Varieties of developmental dyslexia. Cognition, 47(2), 149180. doi: 10.1016/0010-0277(93)90003-e 
Catts, H. W., Fey, M. E., Zhang, X., \& Tomblin, J. B. (1999). Language basis of reading and reading disabilities: Evidence from a longitudinal investigation. Scientific Studies of Reading, 3(4), 331-361. doi: 10.1207/s1532799xssr0304_2

Clarke, P., Hulme, C., \& Snowling, M. (2005). Individual differences in RAN and reading: A response timing analysis. Journal of Research in Reading, 28(2), 73-86. doi: 10.1111/j.1467-9817.2005.00255.x

Coltheart, M. (1978). Lexical access in simple reading tasks. In G. Underwood (Ed.), Strategies of information processing (pp. 151-216). London: Academic Press.

Coltheart, M. (2005). Modeling reading: The dual-route approach. In M. J. Snowling \& C. Hulme (Eds.), The science of reading: A handbook (pp. 6-23). Oxford: Blackwell Publishing Ltd.

Cortese, M., \& Simpson, G. (2000). Regularity effects in word naming: What are they? Memory \& Cognition, 28(8), 1269-1276. doi: 10.3758/BF03211827

Crawford, J. R., Garthwaite, P. H., \& Gault, C. B. (2007). Estimating the percentage of the population with abnormally low scores (or abnormally large score differences) on standardized neuropsychological test batteries: A generic method with applications. Neuropsychology, 21(4), 419-430. doi: 10.1037/0894-4105.21.4.419

Davies, R., Rodríguez-Ferreiro, J., Suárez, P., \& Cuetos, F. (2013). Lexical and sub-lexical effects on accuracy, reaction time and response duration: impaired and typical word and pseudoword reading in a transparent orthography. Reading and Writing, 26(5), 721-738. doi: $10.1007 / \mathrm{s} 11145-012-9388-1$

de Jong, P. F., \& van der Leij, A. (2003). Developmental changes in the manifestation of a phonological deficit in dyslexic children learning to read a regular orthography. Journal of Educational Psychology, 95(1), 22-40. doi: 10.1037/0022-0663.95.1.22 
Denckla, M. B., \& Rudel, R. G. (1976a). Naming of object-drawings by dyslexic and other learning disabled children. Brain and Language, 3(1), 1-15. doi: 10.1016/0093$934 x(76) 90001-8$

Denckla, M. B., \& Rudel, R. G. (1976b). Rapid 'automatized' naming (R.A.N.): Dyslexia differentiated from other learning disabilities. Neuropsychologia, 14(4), 471-479. doi: $10.1016 / 0028-3932(76) 90075-0$

Ehri, L. C. (1995). Phases of development in learning to read words by sight. Journal of Research in Reading, 18(2), 116-125. doi: 10.1111/j.1467-9817.1995.tb00077.x

Everatt, J., Weeks, S., \& Brooks, P. (2008). Profiles of strengths and weaknesses in dyslexia and other learning difficulties. Dyslexia, 14(1), 16-41. doi: 10.1002/dys.342

Fawcett, T. (2006). An introduction to ROC analysis. Pattern Recognition Letters, 27(8), 861874. doi: 10.1016/j.patrec.2005.10.010

Fernandes, S., Ventura, P., Querido, L., \& Morais, J. (2008). Reading and spelling acquisition in European Portuguese: A preliminary study. Reading and Writing, 21(8), 805-821. doi: $10.1007 / \mathrm{s} 11145-007-9093-7$

Festas, I., Martins, C., \& Leitão, J. (2007). Avaliação da compreensão escrita e da leitura de palavras na PAL-PORT [Assessment of reading comprehension and word reading in PAL-PORT]. Revista Educação: Temas e Problemas, 4(2), 223-239.

Finn, E. S., Shen, X., Holahan, J. M., Scheinost, D., Lacadie, C., Papademetris, X., . . . Constable, R. T. (2014). Disruption of functional networks in dyslexia: A whole-brain, data-driven analysis of connectivity. Biological Psychiatry. doi: 10.1016/j.biopsych.2013.08.031

Fletcher, J. M. (2009). Dyslexia: The evolution of a scientific concept. Journal of the International Neuropsychological Society, 15(04), 501-508. doi: $10.1017 / \mathrm{S} 1355617709090900$ 
Frijters, J. C., Lovett, M. W., Steinbach, K. A., Wolf, M., Sevcik, R. A., \& Morris, R. D. (2011). Neurocognitive predictors of reading outcomes for children with reading disabilities. Journal of Learning Disabilities, 44(2), 150-166. doi: 10.1177/0022219410391185

Furnes, B., \& Samuelsson, S. (2009). Preschool cognitive and language skills predicting kindergarten and grade 1 reading and spelling: a cross-linguistic comparison. Journal of Research in Reading, 32(3), 275-292. doi: 10.1111/j.1467-9817.2009.01393.x

Furnes, B., \& Samuelsson, S. (2010). Predicting reading and spelling difficulties in transparent and opaque orthographies: A comparison between Scandinavian and US/Australian children. Dyslexia, 16(2), 119-142. doi: 10.1002/dys.401

Herrmann, J. A., Matyas, T., \& Pratt, C. (2006). Meta-analysis of the nonword reading deficit in specific reading disorder. Dyslexia, 12(3), 195-221. doi: 10.1002/dys.324

Jiménez, J. E., Rodríguez, C., \& Ramírez, G. (2009). Spanish developmental dyslexia:

Prevalence, cognitive profile, and home literacy experiences. Journal of Experimental Child Psychology, 103(2), 167-185. doi: 10.1016/j.jecp.2009.02.004

Kibby, M. Y., \& Cohen, M. J. (2008). Memory functioning in children with reading disabilities and/or attention deficit/hyperactivity disorder: A clinical investigation of their working memory and long-term memory functioning. Child Neuropsychology, 14(6), 525-546. doi: $10.1080 / 09297040701821752$

Kirby, J. R., Georgiou, G. K., Martinussen, R., \& Parrila, R. (2010). Naming speed and reading: From prediction to instruction. Reading Research Quarterly, 45(3), 341-362. doi: 10.1598/RRQ.45.3.4

Kirby, J. R., Parrila, R. K., \& Pfeiffer, S. L. (2003). Naming speed and phonological awareness as predictors of reading development. Journal of Educational Psychology, 95(3), 453464. doi: 10.1037/0022-0663.95.3.453

Krzanowski, W. J., \& Hand, D. J. (2009). ROC curves for continuous data. New York: CRC Press. 
Landerl, K. (2001). Word recognition deficits in German: More evidence from a representative sample. Dyslexia, 7(4), 183-196. doi: 10.1002/dys.199

Landerl, K., Ramus, F., Moll, K., Lyytinen, H., Leppänen, P. H. T., Lohvansuu, K., . . SchulteKörne, G. (2013). Predictors of developmental dyslexia in European orthographies with varying complexity. Journal of Child Psychology and Psychiatry, 54(6), 686-694. doi: 10.1111/jcpp.12029

Landerl, K., \& Wimmer, H. (2008). Development of word reading fluency and spelling in a consistent orthography: An 8-year follow-up. Journal of Educational Psychology, 100(1), 150-161. doi: 10.1037/0022-0663.100.1.150

Martin, J., Colé, P., Leuwers, C., Casalis, S., Zorman, M., \& Sprenger-Charolles, L. (2010). Reading in French-speaking adults with dyslexia. Annals of Dyslexia, 60(2), 238-264. doi: $10.1007 / \mathrm{s} 11881-010-0043-8$

Moura, O., Simões, M. R., \& Pereira, M. (2014). Working memory in Portuguese children with developmental dyslexia. Applied Neuropsychology: Child. doi: $10.1080 / 21622965.2014 .885389$

Nithart, C., Demont, E., Metz-Lutz, M.-N., Majerus, S., Poncelet, M., \& Leybaert, J. (2011). Early contribution of phonological awareness and later influence of phonological memory throughout reading acquisition. Journal of Research in Reading, 34(3), 346363. doi: 10.1111/j.1467-9817.2009.01427.x

Norton, E. S., \& Wolf, M. (2012). Rapid automatized naming (RAN) and reading fluency: Implications for understanding and treatment of reading disabilities. Annual Review of Psychology, 63(1), 427-452. doi: doi:10.1146/annurev-psych-120710-100431

Pennington, B. F., Cardoso-Martins, C., Green, P. A., \& Lefly, D. L. (2001). Comparing the phonological and double deficit hypotheses for developmental dyslexia. Reading and Writing, 14(7), 707-755. doi: 10.1023/a:1012239018038 
Perfetti, C. A., Beck, I., Bell, L. C., \& Hughes, C. (1987). Phonemic knowledge and learning to read are reciprocal: A longitudinal study of first grade children. Merrill-Palmer Quarterly, 33, 283-319.

Ramus, F., Marshall, C. R., Rosen, S., \& van der Lely, H. K. J. (2013). Phonological deficits in specific language impairment and developmental dyslexia: Towards a multidimensional model. Brain, 136(2), 630-645. doi: 10.1093/brain/aws356

Reiter, A., Tucha, O., \& Lange, K. W. (2005). Executive functions in children with dyslexia. Dyslexia, 11(2), 116-131. doi: 10.1002/dys.289

Richlan, F., Kronbichler, M., \& Wimmer, H. (2011). Meta-analyzing brain dysfunctions in dyslexic children and adults. NeuroImage, 56(3), 1735-1742. doi: 10.1016/j.neuroimage.2011.02.040

Savage, R., \& Frederickson, N. (2005). Evidence of a highly specific relationship between rapid automatic naming of digits and text-reading speed. Brain and Language, 93(2), 152-159. doi: 10.1016/j.band1.2004.09.005

Scarborough, H. S. (1990). Very early language deficits in dyslexic children. Child Development, 61(6), 1728-1743. doi: 10.1111/j.1467-8624.1990.tb03562.x

Seymour, P. H. K., Aro, M., \& Erskine, J. M. (2003). Foundation literacy acquisition in European orthographies. British Journal of Psychology, 94(2), 143-174. doi: $10.1348 / 000712603321661859$

Shaywitz, B. A., Lyon, G. R., \& Shaywitz, S. E. (2006). The role of functional magnetic resonance imaging in understanding reading and dyslexia. Developmental Neuropsychology, 30(1), 613-632. doi: 10.1207/s15326942dn3001_5

Silva, C. S., Silva, F. M., \& Martins, M. I. P. (2014). Neuropsychological assessment of children with reading disabilities from 8 to 10 years old: An exploratory Portuguese study. Applied Neuropsychology: Child, 1-10. doi: 10.1080/21622965.2013.838165 
Simões, M. R., Albuquerque, C. P., Pinho, M. S., Pereira, M., Seabra-Santos, M. J., Alberto, I., . . . Lopes, A. F. (in press). Bateria de Avaliação Neuropsicológica de Coimbra (BANC) [Coimbra Neuropsychological Assessment Battery]. Lisboa: Cegoc.

Snowling, M. J. (2006). Language skills and learning to read: The dyslexia spectrum. In M. J. Snowling \& R. Stackhouse (Eds.), Dyslexia, speech and language: A practitioners' handbook (pp. 1-14). Chichester: Wiley.

Sprenger-Charolles, L., Colé, P., Kipffer-Piquard, A., Pinton, F., \& Billard, C. (2009). Reliability and prevalence of an atypical development of phonological skills in Frenchspeaking dyslexics. Reading and Writing, 22(7), 811-842. doi: 10.1007/s11145-0089117-y

Sprenger-Charolles, L., Colé, P., Lacert, P., \& Serniclaes, W. (2000). On subtypes of developmental dyslexia: Evidence from processing time and accuracy scores. Canadian Journal of Experimental Psychology, 54(2), 87-104. doi: 10.1037/h0087332

Sucena, A., Castro, S. L., \& Seymour, P. (2009). Developmental dyslexia in an orthography of intermediate depth: The case of European Portuguese. Reading and Writing, 22(7), 791810. doi: 10.1007/s11145-008-9156-4

Sunseth, K., \& Greig Bowers, P. (2002). Rapid naming and phonemic awareness: Contributions to reading, spelling, and orthographic knowledge. Scientific Studies of Reading, 6(4), 401-429. doi: 10.1207/s1532799xssr0604_05

Swanson, H. L. (1999). Reading comprehension and working memory in learning-disabled readers: Is the phonological loop more important than the executive system? Journal of Experimental Child Psychology, 72(1), 1-31. doi: 10.1006/jecp.1998.2477

Swanson, H. L. (2011). Dynamic testing, working memory, and reading comprehension growth in children with reading disabilities. Journal of Learning Disabilities, 44(4), 358-371. doi: $10.1177 / 0022219411407866$ 
Swets, J. A. (1988). Measuring the accuracy of diagnostic systems. Science, 240(4857), 12851293. doi: $10.1126 /$ science. 3287615

Torgesen, J. K., Wagner, R. K., \& Rashotte, C. A. (1994). Longitudinal studies of phonological processing and reading. Journal of Learning Disabilities, 27(5), 276-286. doi: $10.1177 / 002221949402700503$

Torppa, M., Georgiou, G., Salmi, P., Eklund, K., \& Lyytinen, H. (2012). Examining the doubledeficit hypothesis in an orthographically consistent language. Scientific Studies of Reading, 16(4), 287-315. doi: 10.1080/10888438.2011.554470

Vaessen, A., Bertrand, D., Tóth, D., Csépe, V., Faísca, L., Reis, A., \& Blomert, L. (2010). Cognitive development of fluent word reading does not qualitatively differ between transparent and opaque orthographies. Journal of Educational Psychology, 102(4), 827842. doi: $10.1037 / \mathrm{a} 0019465$

Vaessen, A., Gerretsen, P., \& Blomert, L. (2009). Naming problems do not reflect a second independent core deficit in dyslexia: Double deficits explored. Journal of Experimental Child Psychology, 103(2), 202-221. doi: 10.1016/j.jecp.2008.12.004

Vellutino, F. R., Fletcher, J. M., Snowling, M. J., \& Scanlon, D. M. (2004). Specific reading disability (dyslexia): What have we learned in the past four decades? Journal of Child Psychology and Psychiatry, 45(1), 2-40. doi: 10.1046/j.0021-9630.2003.00305.x

Vukovic, R. K., \& Siegel, L. S. (2006). The double-deficit hypothesis: A comprehensive analysis of the evidence. Journal of Learning Disabilities, 39(1), 25-47. doi: $10.1177 / 00222194060390010401$

Wagner, R. K., \& Torgesen, J. K. (1987). The nature of phonological processing and its causal role in the acquisition of reading skills. Psychological Bulletin, 101(2), 192-212. doi: 10.1037/0033-2909.101.2.192

Wagner, R. K., Torgesen, J. K., \& Rashotte, C. A. (1994). Development of reading-related phonological processing abilities: New evidence of bidirectional causality from a latent 
variable longitudinal study. Developmental Psychology, 30(1), 73-87. doi: $10.1037 / 0012-1649.30 .1 .73$

Wechsler, D. (2003). Escala de Inteligência de Wechsler para Crianças - Terceira Edição [Wechsler Intelligence Scale for Children - Third Edition (WISC-III) - Portuguese Version (M. R. Simões, A. M. Rocha, and C. Ferreira)]. Lisbon: Cegoc.

Willburger, E., Fussenegger, B., Moll, K., Wood, G., \& Landerl, K. (2008). Naming speed in dyslexia and dyscalculia. Learning and Individual Differences, 18(2), 224-236. doi: 10.1016/j.lindif.2008.01.003

Wimmer, H., Mayringer, H., \& Landerl, K. (2000). The double-deficit hypothesis and difficulties in learning to read a regular orthography. Journal of Educational Psychology, 92(4), 668-680. doi: 10.1037/0022-0663.92.4.668

Wolf, M., \& Bowers, P. G. (1999). The double-deficit hypothesis for the developmental dyslexias. Journal of Educational Psychology, 91(3), 415-438. doi: 10.1037/00220663.91.3.415

Wolf, M., \& Bowers, P. G. (2000). Naming-speed processes and developmental reading disabilities: An introduction to the special issue on the double-deficit hypothesis. Journal of Learning Disabilities, 33(4), 322-324. doi: 10.1177/002221940003300404

Wolf, M., Bowers, P. G., \& Biddle, K. (2000). Naming-speed processes, timing, and reading. Journal of Learning Disabilities, 33(4), 387-407. doi: 10.1177/002221940003300409

Ziegler, J. C., Bertrand, D., Tóth, D., Csépe, V., Reis, A., Faísca, L., . . Blomert, L. (2010). Orthographic depth and its impact on universal predictors of reading: A cross-language investigation. Psychological Science, 21(4), 551-559. doi: 10.1177/0956797610363406

Ziegler, J. C., \& Goswami, U. (2005). Reading acquisition, developmental dyslexia, and skilled reading across languages: A psycholinguistic grain size theory. Psychological Bulletin, 131(1), 3-29. doi: 10.1037/0033-2909.131.1.3 

Table 1

Pearson correlation coefficients between general intellectual ability, phonological processing and reading measures

\begin{tabular}{|c|c|c|c|c|c|c|c|c|c|}
\hline & 2 & 3 & 4 & 5 & 6 & 7 & 8 & 9 & 10 \\
\hline 1. WISC-III FSIQ & $.450^{* *}$ & $.586^{* *}$ & .133 & $.343^{* *}$ & .185 & $.259^{*}$ & .226 & $.284^{*}$ & $.284^{*}$ \\
\hline 2. PA Deletion & & $.812^{* *}$ & $.624^{* *}$ & $.422^{* *}$ & $.473^{* *}$ & $.648^{* *}$ & $.733^{* *}$ & $.561^{* *}$ & $.720^{* *}$ \\
\hline 3. PA Substitution & & & $.558^{* *}$ & $.468^{* *}$ & $.547^{* *}$ & $.629^{* *}$ & $.652^{* *}$ & $.623^{* *}$ & $.648^{* *}$ \\
\hline 4. RAN & & & & $.382^{* *}$ & $.557^{* *}$ & $.656^{* *}$ & $.596^{* *}$ & $.507^{* *}$ & $.536^{* *}$ \\
\hline 5. Forward Digit Span & & & & & $.446^{* *}$ & $.393^{* *}$ & $.356^{* *}$ & $.384^{* *}$ & $.327^{* *}$ \\
\hline 6. Reading Fluency & & & & & & $.601^{* *}$ & $.587^{* *}$ & $.657^{* *}$ & $.449^{* *}$ \\
\hline 7. Reading Accuracy & & & & & & & $.702^{* *}$ & $.694^{* *}$ & $.683^{* *}$ \\
\hline 8. Regular Words & & & & & & & & $.638^{* *}$ & $.648^{* *}$ \\
\hline 9. Irregular Words & & & & & & & & & $.571^{* *}$ \\
\hline
\end{tabular}

Note. ${ }^{*} p<.05,{ }^{* *} p<.01$. WISC-III FSIQ = Wechsler Intelligence Scale for Children (Third Edition) Full Scale IQ. PA = phonological awareness. RAN = rapid automatized naming. 
Table 2

Means, standard deviations and post hoc comparisons of phonological processing and reading for children with developmental dyslexia and controls

\begin{tabular}{|c|c|c|c|c|}
\hline & $\mathrm{CA}$ & $\mathrm{RL}$ & $\mathrm{DD}$ & Post hoc \\
\hline & $M \pm S D$ & $M \pm S D$ & $M \pm S D$ & $\begin{array}{l}\text { comparisons } \\
\text { (Bonferroni) }\end{array}$ \\
\hline \multicolumn{5}{|l|}{ Phonological Processing } \\
\hline PA Deletion ${ }^{a}$ & $10.79 \pm 1.86$ & $10.26 \pm 2.55$ & $4.42 \pm 1.76$ & $\mathrm{CA}=\mathrm{RL}>\mathrm{DD}$ \\
\hline PA Substitution ${ }^{a}$ & $12.00 \pm 2.82$ & $9.95 \pm 2.99$ & $4.79 \pm 2.58$ & $\mathrm{CA}>\mathrm{RL}>\mathrm{DD}$ \\
\hline $\mathrm{RAN}^{\mathrm{a}}$ & $11.63 \pm 2.85$ & $10.54 \pm 2.63$ & $6.12 \pm 3.12$ & $\mathrm{CA}=\mathrm{RL}>\mathrm{DD}$ \\
\hline Forward Digit Span ${ }^{b}$ & $0.84 \pm 1.52$ & $0.06 \pm 1.03$ & $-0.91 \pm 1.16$ & $\mathrm{CA}=\mathrm{RL}>\mathrm{DD}$ \\
\hline \multicolumn{5}{|l|}{ Reading Text } \\
\hline Reading Fluency $^{c}$ & $100.35 \pm 27.10$ & $59.27 \pm 8.95$ & $56.59 \pm 20.88$ & $\mathrm{CA}>\mathrm{RL}=\mathrm{DD}$ \\
\hline Reading Accuracy ${ }^{\mathrm{d}}$ & $98.77 \pm 0.75$ & $97.29 \pm 1.58$ & $92.62 \pm 6.25$ & $\mathrm{CA}=\mathrm{RL}>\mathrm{DD}$ \\
\hline \multicolumn{5}{|l|}{ Reading Words } \\
\hline Regular Words ${ }^{\mathrm{d}}$ & $97.65 \pm 4.04$ & $88.28 \pm 11.84$ & $76.82 \pm 13.09$ & $\mathrm{CA}>\mathrm{RL}>\mathrm{DD}$ \\
\hline Irregular Words ${ }^{\mathrm{d}}$ & $83.33 \pm 10.37$ & $72.91 \pm 6.81$ & $61.45 \pm 15.27$ & $\mathrm{CA}>\mathrm{RL}>\mathrm{DD}$ \\
\hline Pseudowords ${ }^{\mathrm{d}}$ & $88.54 \pm 9.69$ & $89.58 \pm 13.62$ & $57.81 \pm 20.79$ & $\mathrm{CA}=\mathrm{RL}>\mathrm{DD}$ \\
\hline
\end{tabular}

Note. ${ }^{\mathrm{a}}$ age-scaled score. ${ }^{\mathrm{b}}$ age-adjusted score (unstandardized residual score). ${ }^{\mathrm{c}}$ number of correctly read words in one minute. ${ }^{\mathrm{d}}$ percentage of correctly read words. $\mathrm{PA}=$ phonological awareness. $\mathrm{RAN}=$ rapid automatized naming. $\mathrm{CA}=$ chronological-age-matched controls. $\mathrm{RL}=$ reading-level-matched controls. $\mathrm{DD}=$ children with developmental dyslexia. 
Table 3

Receiver operating characteristics (ROC) curve analysis

\begin{tabular}{|c|c|c|c|c|}
\hline & \multicolumn{2}{|c|}{ CA vs. DD } & \multicolumn{2}{|c|}{ RL vs. DD } \\
\hline & AUC & $S E$ & AUC & $S E$ \\
\hline PA Deletion & $.980^{* * *}$ & .019 & $.957^{* * *}$ & .028 \\
\hline PA Substitution & $.974^{* * *}$ & .020 & $.906^{* * *}$ & .042 \\
\hline RAN & $.905^{* * *}$ & .044 & $.858^{* * *}$ & .053 \\
\hline Forward Digit Span & $.831^{* * *}$ & .058 & $.734^{* *}$ & .074 \\
\hline
\end{tabular}

Note. ${ }^{*} p<.05,{ }^{* *} p<.01,{ }^{* * *} p<.001 . \mathrm{PA}=$ phonological awareness. $\mathrm{RAN}=$ rapid automatized naming. $\mathrm{CA}=$ chronological-age-matched controls. $\mathrm{RL}=$ reading-level-matched controls. $\mathrm{DD}=$ children with developmental dyslexia. $\mathrm{AUC}=$ area under the curve. $S E=$ standard error. 
Table 4

Hierarchical linear regression analyses for reading

\begin{tabular}{|c|c|c|c|c|c|c|c|}
\hline Dependent Variable & Block & Predictors & $R^{2}$ & $\Delta R^{2}$ & $\beta$ & $t$-test & $p r^{2}$ \\
\hline \multirow[t]{4}{*}{ Text Reading Fluency } & 1 & Age & .152 & & .390 & $3.547 * *$ & .152 \\
\hline & 2 & PA & .712 & .560 & .352 & $3.946 * * *$ & .067 \\
\hline & & RAN & & & .440 & $5.151 * * *$ & .114 \\
\hline & & FDS & & & .113 & 1.486 & .009 \\
\hline \multirow[t]{4}{*}{ Text Reading Accuracy } & 1 & Age & .007 & & .082 & 0.685 & .006 \\
\hline & 2 & PA & .558 & .551 & .431 & $3.901 * * *$ & .100 \\
\hline & & RAN & & & .405 & $3.843 * * *$ & .097 \\
\hline & & FDS & & & .036 & 0.387 & .001 \\
\hline \multirow[t]{4}{*}{ Reading Regular Words } & 1 & Age & .001 & & .024 & 0.199 & .001 \\
\hline & 2 & PA & .614 & .613 & .628 & $6.084 * * *$ & .213 \\
\hline & & RAN & & & .287 & $2.915^{* *}$ & .048 \\
\hline & & FDS & & & .049 & 0.555 & .001 \\
\hline \multirow[t]{4}{*}{ Reading Irregular Words } & 1 & Age & .020 & & .143 & 1.210 & .020 \\
\hline & 2 & PA & .519 & .499 & .533 & $4.627 * * *$ & .153 \\
\hline & & RAN & & & .242 & $2.203 *$ & .034 \\
\hline & & FDS & & & .042 & 0.424 & .001 \\
\hline \multirow[t]{4}{*}{ Reading Pseudowords } & 1 & Age & .068 & & .260 & $2.256^{*}$ & .067 \\
\hline & 2 & PA & .533 & .465 & .619 & $5.449 * * *$ & .207 \\
\hline & & RAN & & & .140 & 1.292 & .011 \\
\hline & & FDS & & & .017 & 0.176 & .001 \\
\hline
\end{tabular}

Note. ${ }^{*} p<.05,{ }^{* *} p<.01,{ }^{* * *} p<.001 . R^{2}$ and $\Delta R^{2}=$ variance explained. $\beta=$ standardized regression coefficient. $p r^{2}$

$=$ squared part correlation, represents the unique variance of each predictor. $\mathrm{PA}=$ phonological awareness. $\mathrm{RAN}$

$=$ rapid automatized naming. FDS $=$ Forward task from the Digit Span. 